\title{
A APRENDIZAGEM DA ATENÇÃO NA COGNIÇÃO INVENTIVA
}

\author{
Virgínia Kastrup \\ Universidade Federal do Rio de Janeiro
}

RESUMO: O artigo aborda o problema da aprendizagem da atenção, tomando como base a noção de cognição como invenção (KASTRUP, 1999). Para o estudo da atenção examina trabalhos onde, no contexto das ciências cognitivas contemporâneas, esta é concebida como fundo de variação da cognição, ultrapassando sua manifestação como ato de prestar atenção. Analisa a relação entre atenção e aprendizagem na prática do devir-consciente proposta por Depraz, Varela e Vermersch (2003), onde se destaca a suspensão da atitude natural, a atenção a si e uma mudança na qualidade da atenção, que passa de um ato de busca de informações para um ato de encontro com a dimensão de virtualidade do si. A aprendizagem da atenção é examinada em sua lógica circular, temporal e coletiva. As diferenças entre distração e dispersão, bem como entre concentração e focalização são discutidas no que diz respeito a seu papel na cognição inventiva.

PALAVRAS-CHAVE: atenção - aprendizagem - devir-consciente

\section{THE LEARNING OF ATTENTION IN INVENTIVE COGNITION IS THE PROBLEM OF THIS ARTICLE.}

ABSTRACT: The learning of attention is the problem this article is concerned with, assuming the notion of cognition as invention (KASTRUP, 1999). Within the context of contemporary cognitive sciences, we examine the investigations in which attention is conceived as the background of variation of cognition, rather than its manifestation as an act of paying attention. We analyze the relationship between attention and learning in the practice of becoming aware, as proposed by Depraz, Varela and Vermersch (2003), which includes the suspension of natural attitude, the redirection of attention to oneself, and modification in the quality of attention, which then, becomes an act of finding the virtual self, instead of an act of searching for information. The learning of attention is analyzed through a logic that is circular, temporal and collective. The differences between distraction and dispersiveness, and between concentration and focusing are discussed in relation to their role in inventive cognition.

KEY-WORDS: attention - learning - becoming aware

O problema da aprendizagem da atenção tem tido lugar de destaque na atualidade. Um dos motivos é que o funcionamento da atenção no mundo contemporâneo vem assumindo uma característica marcante. É possível observar que a atenção desliza incessantemente entre fatos e situações, transparecendo uma certa dificuldade de concentração. Numa busca acelerada de novidade a atenção é passageira, muda constantemente de foco e é sujeita ao esgotamento em frações de segundos. Quando se procura descrever como a atenção funciona nos dias atuais, o primeiro aspecto que sobressai é uma acentuada dispersão, que resulta da mudança constante do foco da atenção. Não é difícil perceber que alguns fatores participam da produção desse tipo de subjetividade. As imagens e textos constantemente veiculados pela mídia, bem como a explosão recente das tecnologias da informação, como é o caso Internet, torna dis- ponível uma avalanche de informações, atravessando grandes distâncias em alguns segundos. Por sua vez, os celulares são também fatores importantes, atravessando sem cessar o fluxo da vida cotidiana. Observa-se que há neste quadro de coisas algo que é da ordem da quantidade. Há na sociedade contemporânea um excesso de informação e uma velocidade acelerada que convoca uma mudança constante do foco da atenção, em função dos apelos que se multiplicam sem cessar.

Os problemas de atenção comparecem hoje em dia na escola, na clínica, nos ambientes de trabalho e nas famílias. É cada vez mais freqüente o diagnóstico de TDA - transtorno de déficit de atenção - que tem como sintomas baixo rendimento na realização de tarefas, dificuldade de seguir regras e desenvolver projetos de longo prazo, e a cujo quadro pode estar associado a hiperatividade e à impulsividade. No contexto escolar o problema 
é diretamente colocado como incidindo sobre a atenção que é requerida no processo de aprendizagem. Considera-se que a criança não aprende porque não presta atenção. Esse funcionamento da atenção na subjetividade contemporânea não é tratado como um problema de ordem moral, sendo antes tomado como um transtorno que exige tratamento (CRARY, 2001). Muitas crianças são encaminhadas para terapias de enfoque cognitivocomportamental, que têm em vista aumentar a capacidade de atenção para a realização de tarefas. O que prevalece nesse domínio é o entendimento da cognição como processo de solução de problemas e, no que diz respeito à atenção, a ênfase recai sobre seu papel no controle do comportamento e na realização de tarefas. Ela é a condição para que se dê o processo de aprendizagem, a solução de problemas e o desempenho de tarefas cognitivas. Tomada como uma espécie de processo subsidiário à aprendizagem e estando a seu serviço, sua análise é restrita à atenção voltada para objetos e estímulos do mundo externo, ou seja, para a captação e busca de informações. A falha no trato com as informações externas é sinal de pouca atenção e baixa capacidade de concentração. Tendo em vista que a noção de cognição é restrita à solução de problemas e que a proposta clínica é declaradamente adaptativa, a questão é como restabelecer a capacidade de prestar atenção, ou seja, como promover a aprendizagem de uma atenção que é necessária à realização de tarefas.

A noção de déficit indica que subjaz aí um entendimento da atenção como marcada por um funcionamento binário: 0-1, atenção-desatenção. Tudo aquilo que escapa ao ato de prestar atenção fica alocado na rubrica do negativo, da falta, do déficit. Ao procurar fazer frente ao funcionamento da atenção que foge da tarefa, são igualmente consideradas indesejáveis a dispersão e a distração. No entanto, os fenômenos são distintos. A dispersão consiste num repetido deslocamento do foco atencional, que impossibilita a concentração, a duração e a consistência da experiência. Um exemplo é a pessoa que tenta assistir televisão, mas passa a noite inteira zapeando os canais, agarrada ao controle remoto que a conduz de um programa a outro. Ao final da noite ela sabe quais os programas que passaram na TV, embora de fato não tenha assistido a nenhum deles. Uma certa avidez de novidade impede a espessura temporal e a consistência da experiência. Já a distração é um funcionamento onde a atenção vagueia, experimenta uma errância, fugindo do foco da tarefa para a qual é solicitado prestar atenção e indo na direção de um campo mais amplo, habitado por pensamen- tos fora de lugar, percepções sem finalidade, reminiscências vagas, objetos desfocados e idéias fluidas, que advêm do mundo interior ou exterior, mas que têm em comum o fato de serem refratárias ao apelo da tarefa em questão. É curioso notar que o distraído é alguém extremamente concentrado, que não é meramente desatento, mas cuja atenção se encontra em outro lugar. Vale notar que ao restringir a atenção ao ato de prestar atenção, identifica-se o processo de concentração ao de focalização, que como veremos não se sobrepõem, pois pode haver focalização sem concentração e também concentração sem foco. A primeira prevalece no regime cognitivo que é hegemônico na subjetividade contemporânea, enquanto a segunda revelar-se-á fundamental no processo de invenção. Cabe ainda sublinhar que, ainda que diversos autores considerem que o TDA seja em parte causado pelas características da sociedade atual (além da predisposição genética), ele é tratado como um problema individual, aliando técnicas comportamentais e medicamentos como a ritalina (metilfenidato).

Neste artigo procuraremos argumentar que estudos recentes sobre atenção que são desenvolvidos no campo das ciências cognitivas contemporâneas promovem uma discussão detalhada sobre o tema, que ainda precisa ser assimilada pelas abordagens psicológicas da cognição, tanto teóricas quanto clínicas. É patente que o problema da atenção exige uma discussão mais fina quando trabalhamos com uma noção de cognição ampliada, que extrapola o processo de solução de problemas, mas se define como invenção de si e do mundo (KASTRUP, 1999). Do ponto de vista da invenção, a cognição não se limita a um funcionamento regido por leis e princípios invariantes que ocorreriam entre um sujeito e um objeto pré-existentes, entre o eu e o mundo. Ela é uma prática de invenção de regimes cognitivos diversos, co-engendrando, ao mesmo tempo, o si e o mundo, que passam à condição de produtos do processo de invenção. Cabe ressaltar que a idéia de co-engendramento encontra apoio na noção de causalidade circular proposta por Francisco Varela (VARELA, S/D; DUPUY E VARELA, 1995) e retornaremos a ela posteriormente. Com Varela (1995) afirmamos que a cognição inclui a invenção de problemas. A aprendizagem inventiva inclui a experiência de problematização, que se revela através de breakdowns, que constituem rupturas no fluxo cognitivo habitual. Problema e solução são as duas faces do processo da aprendizagem inventiva.

Desta perspectiva, cabe investigar qual o estatuto e o papel da atenção na cognição inventi- 
va. Frente a este modo de colocar o problema, que introduz a dimensão temporal e coletiva da cognição, surge uma série de perguntas: Seria a atenção um processo único e homogêneo, variando apenas na proporção do investimento do eu sobre os objetos e tarefas? Haveria um funcionamento cognitivo onde a atenção estaria ausente, podendo ser denominado estado de desatenção? Trata-se da mesma atenção quando estamos frente a uma obra de arte e quando buscamos a solução de um problema matemático? É a mesma atenção que é mobilizada quando lemos um texto literário e quando assistimos a um programa de TV? Como colocar o problema da relação entre atenção e aprendizagem? Seria a atenção condição ou efeito da aprendizagem? Neste artigo procuraremos demonstrar que, perspectivado pela noção de cognição inventiva, o problema da aprendizagem da atenção envolve, em primeiro lugar, uma ampliação do conceito de atenção em relação ao ato de prestar atenção a tarefas e de buscar informações. Em segundo lugar, modifica-se o modo de colocar o problema da relação entre atenção e aprendizagem. O problema de atenção que é requerida para que um processo de aprendizagem tenha lugar é substituído pelo problema da própria aprendizagem da atenção. Com esta nova inflexão, o objetivo é discutir a lógica temporal de tal aprendizagem, bem como sua dimensão coletiva. O que está em jogo é o entendimento de que a atenção nem sempre é um processo pilotado por um eu, fonte e centro do processo de conhecimento. A questão da aprendizagem da atenção desdobra-se então em duas outras: a da amplitude do funcionamento da atenção e a do mecanismo que liga aprendizagem e atenção.

\section{EXPLORANDO O FUNCIONAMENTO DA ATENÇÃO}

No cenário atual das ciências cognitivas, o tema da atenção tem sido investigado no âmbito dos estudos da consciência, que ganham destaque na década de 90 . Tais estudos, que haviam sido abandonados com a hegemonia do behaviorismo, são então retomados e o desafio agora é não apenas a investigação da mente, que já havia sido resgatada na década de 60 , mas da cognição em sua dimensão de experiência. Tais investigações, que rompem com o veto positivista de uma ciência da experiência, visam transformar o que era considerado um mistério num problema (SEARLE, 1998). Dentre os inúmeros trabalhos que surgiram nessa direção, destacam-se alguns que contribuem para o entendimento da atenção do ponto de vista da cognição inventiva.

Arvidson (2000) considera que uma série de mal entendidos são gerados pela suposta correspondência entre a consciência e o foco da atenção. Discordando da posição defendida por G. Strawson (1997), afirma que seria absurdo acreditar que a consciência pode "sair de férias". Recorrendo à abordagem fenomenológica de Aron Gurwitsch, Arvidson afirma que a consciência não se reduz ao foco da atenção, mas possui uma organização tridimensional, comportando tema, campo temático e margem. O tema corresponde ao foco da atenção, àquilo que é dotado de interesse; o campo temático diz respeito àquilo que está relacionado ao tema e que se encontra ligado a ele numa unidade de relevância; a margem é formada por tudo aquilo que se apresenta como irrelevante para o tema em questão. Segundo Arvidson, a atenção desliza entre os três níveis, num movimento de vaivém. Neste caso, a consciência não nos abandona em determinados momentos, mas permanece sempre presente, ainda que a atenção não incida sobre um foco específico. $\mathrm{O}$ que surge então é uma concepção não-egóica da consciência. Por sua continuidade temporal, é certo que a consciência vem a produzir o senso de um eu contínuo, mas este não é o fundamento da consciência. Ele possui uma continuidade fraca, se comparada à visão do eu como centro e fonte de toda atividade consciente. Varela, Thompson e Rosch (2003) afirmam que o eu é uma formação que emerge e desaparece a partir de um fundo processual da cognição que é pré-egóico, composto de redes sub-simbólicas e elementos não representacionais. A idéia de um eu como entidade permanente e substancial é da ordem da crença. Inspirados na prática budista, afirmam que nas tradições orientais as práticas de meditação visam a expansão do campo da atenção, tornandoa mais sensível e aberta através do abandono de padrões habituais e do próprio eu. Argumentam que agir em conformidade com a vontade do eu é uma atitude menos livre, presa ao passado por histórias de condicionamento que resultam na repetição de padrões habituais no futuro. A proposta das práticas de meditação budistas não é afastar o sujeito do mundo, mas, ao contrário, capacitar a atenção e a consciência a estarem totalmente presentes na experiência. $\mathrm{O}$ tema da atenção ao presente surge como uma abertura da consciência para uma experiência que não é recoberta pela história passada e que está associada ao fato de ser destituída de um eu. Diversos autores também têm questionado a teoria de J. Broadbent do canal único da atenção, que a restringe a um processo de seleção de informações, a serem processadas de modo linear, através de seqüências de 
inputs e outputs. Os críticos têm enfatizado que a atenção não é como um tubo, mas possui uma estrutura folheada, comportando a coexistência de processos cognitivos paralelos e simultâneos (CAMUS, 1996; MIALET, 1999; VERMERSCH, 2002a; 2002b). Tais trabalhos constituem referências importantes para dar conta da complexidade do problema da atenção e da consciência na atualidade.

Pierre Vermersch (2002a, p.27) afirma que a atenção e consciência são um mesmo objeto, encarado de dois pontos de vista diferentes. Escolher o ponto de vista da atenção significa apreender a consciência em suas propriedades funcionais e em suas transformações dinâmicas. $\mathrm{O}$ estudo da atenção revela, não o aspecto de intencionalidade da consciência, mas sua dimensão de variação e modulação. A idéia central é que a modulação modifica a estrutura intencional da consciência. $O$ conceito de intencionalidade, proposto por Brentano, visa a apontar que a consciência se define por sua abertura para o mundo, que a consciência é sempre consciência de algo. Sem afastar-se da fenomenologia, Vermersch sublinha, entretanto, que o funcionamento da atenção atesta que este voltar-se para o mundo é sujeito a modulações, que fazem com que a consciência varie em clareza e distinção. Em sua minuciosa investigação, Vermersch ressalta que a atenção não é um processo específico, mas que vem sempre acoplado a outros, como a percepção e a memória, possuindo um funcionamento transversal. A atenção não tem uma atualização específica como a percepção tem o percepto e a memória a lembrança, e aí parece encontrar-se a fonte dos mal entendidos que acabam por fazer dela um processo subsidiário. Entretanto, este caráter transversal faz da atenção um processo especial a partir do momento em que ele é entendido como fundo de variação da cognição. Como teremos ocasião de demonstrar, este caráter de modulação da intencionalidade será importante para o entendimento do papel da atenção na cognição inventiva.

As pesquisas levadas à frente no fim do século XX promovem uma retomada dos estudos desenvolvidos pela psicologia e filosofia da segunda metade do século XIX, que também dão testemunho de que a atenção não se restringe ao ato de prestar atenção. A distinção proposta por W. James (1890/1945) entre foco e margem da consciência indica o caráter seletivo, mas também fluido da atenção. Segundo Arvidson (2000), mais do que o problema da seleção, o importante na abordagem jamesiana é o exame da atenção no con- texto da teoria do fluxo da consciência, pois ela responde pelo movimento da consciência. James aponta que o funcionamento da atenção voluntária opera por puxões, por sacudidelas que buscam recolocar repetidamente no foco uma atenção cuja tendência é escapar a todo momento. Ou seja, a seleção operada pela vontade e pelo eu encontra resistência para sua efetivação, demandando um esforço reiterado para manter-se no foco. E. Husserl afirma que se experimentarmos fixar a percepção num único objeto, podemos ter a medida da oscilação a que somos acometidos, independentemente do esforço da vontade consciente. A percepção vagueia e escapa do objeto visado e somos então capazes de flagrar a presença da atenção (VERMERSCH, 2002b). H. Bergson (1934/1962) tem como importante contribuição apontar a existência de uma atenção à duração, que é como uma atenção suplementar, que não se confunde com aquela voltada para a vida prática e para os imperativos da ação. A atenção à vida prática está envolvida nas atividades ordinárias da vida cotidiana, sendo portanto utilitária. Já a atenção suplementar caracteriza um mergulho na duração, sendo evidenciada sobretudo na arte e na filosofia. Na mesma época, embora num outro contexto, Freud (1912/1969) estabelece o conceito de atenção flutuante, destacando-a como aquela a ser exercida pelo analista no setting clínico, posto que necessária à escuta sintonizada com as associações inconscientes trazidas pelo paciente. Sem pretender entrar no exame detalhado e na análise dos desdobramentos e limites de cada uma dessas contribuições, parece-nos pertinente apontar a existência de um arco ligando o final do século XIX e o final do século XX. Nas duas extremidades deste arco, encontramos o problema da atenção em sua complexidade e amplitude, para além do ato de prestar atenção que é mobilizado na realização de tarefas.

Depraz, Varela e Vermersch $(2002 ; 2003)$ propõem uma contribuição original ao estudo da atenção a partir do conceito de devir-consciente. O desafio dos autores é investigar a experiência humana em ato, e não apenas os conteúdos da experiência. $\mathrm{O}$ devir-consciente é o ato de tornar explícito, claro e intuitivo algo que nos habitava de modo pré-reflexivo, opaco e afectivo. Trata-se de conhecer a experiência humana em seu caráter de atividade, de prática, ressaltando seu caráter mutável e fluido. A proposta do livro On becoming aware (2003) é desenvolver uma metodologia para sua investigação, para a qual sugerem o aprendizado de uma atitude cognitiva que implica diretamente no problema do aprendizado da atenção. 
A inspiração de Depraz, Varela e Vermersch é o método da époché ou método da redução fenomenológica, formulado por E. Husserl. Os autores sublinham que agentes cognitivos concretos encontram sempre dificuldades em efetivar a redução, que envolve a suspensão da atitude natural que consiste em realizar juízos sobre o mundo. Cabe ressaltar que a questão das dificuldades e obstáculos da redução não havia sido colocada por Husserl, que falava no método da redução como colocação entre parênteses do juízo por parte do sujeito transcendental. Procurando torná-lo um método concreto, os autores propõem o que denominam uma pragmática fenomenológica. Nesta direção, o ciclo básico da redução é desdobrado em três gestos ou atos: suspensão, redireção e deixar vir. A suspensão da atitude natural, ou seja, a suspensão da atitude cognitiva de juízo, pode ser desencadeada por um acontecimento especial, que interrompe o fluxo cognitivo habitual. Um dos exemplos mais reveladores é a surpresa estética. $\mathrm{O}$ acontecimento estético tem a propriedade de gerar uma experiência não antecipável, uma surpresa, que desativa a atitude recognitiva e instala um estado de exceção. A suspensão pode ser entendida tanto como uma interrupção do fluxo cognitivo quanto como suspensão no tempo. Os dois outros atos do ciclo básico tocam diretamente no problema da atenção. Com o ato de suspensão, a atenção é redirecionada do exterior - para onde ela é habitualmente voltada - para o interior. A atenção a si é então o segundo ato do ciclo básico. Tomando como base a experiência estética, pode-se dizer então que a relação com a obra de arte instala uma relação consigo já marcada pela suspensão da tendência recognitiva. Quando a atenção sofre essa dobra do exterior para o interior, não aciona um processo de consciência de si nem de reflexão. Tendo em vista que o ato ocorre sob suspensão, a relação consigo não dá lugar a lembranças, pensamentos ou preocupações. Ao contrário, o recolhimento pode ser dito um movimento de saída de si. Detecta-se então um terceiro gesto cognitivo, que transforma a qualidade da atenção. Ele é nomeado em inglês letting-go, em francês lâcher-prise e pode ser traduzido em português como deixar vir. A atenção que busca é transmutada numa atenção que encontra, que acolhe elementos opacos e afectivos que nos habitavam num plano pré-egóico ou pré-reflexivo. Esta segunda qualidade da atenção caracteriza uma concentração aberta, destituída de intencionalidade e de foco. Um exemplo desta atenção ao mesmo tempo concentrada e sem foco é aquela mobilizada na visão estereoscópica, quando nos esforçamos para ver uma figura em 3D emergir de um fundo de formas indefinidas. Para que a emergência da figura ocorra é preciso olhar sem ver. Poderia tratar-se também de escutar sem ouvir, mas sempre de deixar vir algo que não é visado pela consciência intencional. A emergência intuitiva, explícita e clara finaliza o processo de devirconsciente. Cabe notar que esta concentração sem focalização, embora compareça na vida cotidiana, não está em geral envolvida na realização de tarefas. Vale ressaltar que os três gestos acima não seguem uma ordem linear e sequencial. Cada gesto ultrapassa, ao mesmo tempo que conserva o anterior. Sendo assim, eles devem ser entendidos como fazendo parte de um ciclo, se entrelaçando e operando um movimento circular.

A questão é como cultivar o ato do devirconsciente que é composto desses três gestos, através de práticas concretas. As práticas propostas são diversas: a meditação budista, a entrevista de explicitação, a reza do coração, a clínica, a sessão de escrita, o aprendizado da filosofia e a própria visão estereoscópica, reconhecendo os autores que esta não é uma lista exaustiva e fechada. Estes exemplos revelam que as práticas de aprendizagem da atenção que estão em jogo aqui não se esgotam enquanto prática de pesquisa, assumindo diversas vezes a feição de práticas de transformação de si e de relação consigo. Por outro lado, há uma notável modificação do problema da atenção quando a cognição é colocada em suspensão. Redirecionada para o interior, a atenção não acessa representações e não funciona no registro do eu: eu penso, eu sei etc. Na ausência de preenchimento imediato, a atenção atravessa um vazio, um intervalo temporal que se revela como espera. Esta espera é considerada como o maior obstáculo para que a redução se cumpra, pois é necessário que a atenção aberta seja sustentada para acolher aquilo que, vindo de si, revela a dimensão de virtualidade do si. Por sua vez, se o acolhimento de algo desta natureza se dá, a atenção colocanos em contato com uma distância íntima, algo que nos habita, mas que não é do conhecimento nem está sob o controle do eu. Neste caso, tais práticas de aprendizagem da atenção são práticas de presença a si onde a atenção acessa o fundo processual e inventivo da cognição.

\section{A LÓGICA TEMPORAL DO APRENDIZADO}

O devir-consciente é uma prática e sua efetuação não pode ser aprendida nos livros, não se prestando a uma aprendizagem teórica ou simbólica. Usando uma distinção proposta por John Dewey, trata-se antes de saber fazer (know how) 
do que de saber algo (know that). Aprende-se fazendo, ou melhor, aprende-se no trabalho atento (learning on the job), e não através do exercício mecânico. É a atenção que é treinada. Numa certa medida, a aprendizagem é como a de uma habilidade, no sentido em que, num trabalho de longo prazo, ocorre um processo de estabilização da épochè que faz com que ela apareça como um gesto espontâneo e sem esforço. Por outro lado, o exemplo que é evocado é o da habilidade musical. Como em outros momentos da obra de Varela, a aprendizagem da música é tomada como paradigmática (VARELA, THOMPSON E ROSCH, 2003). Como sublinhamos em outra ocasião (KASTRUP, 1999) a aprendizagem de tocar um instrumento revela uma dimensão que ultrapassa aquela de solução de problemas e de adaptação a um mundo pré-existente, indicando a invenção recíproca e indissociável de si e do mundo, como no caso, do músico e da música. Aprender resta sendo antes uma questão de invenção do que de adaptação. Varela, Depraz e Vermersch (2003) abordam novamente a aprendizagem tomando a arte como caso exemplar. Neste momento, a referência à experiência estética serve para revelar o exercício de uma atenção distinta daquela envolvida na realização de tarefas. A arte mobiliza e desenvolve, em sua aprendizagem, uma atitude atencional ao mesmo tempo concentrada e aberta. Os autores ressaltam que esta envolve não apenas tocar, reger e compor, mas também o tornar-se mais sensível em ouvir música, deixandose tocar por ela em toda sua força (p.99). Fica claro aqui que a habilidade musical não é meramente técnica, nem visa um adestramento apenas muscular e mecânico. Está envolvida aí uma aprendizagem da sensibilidade, o que significa a aprendizagem de uma atenção especial que encontra a música, deixando-se afetar por ela e acolhendo seus efeitos sobre si. Os autores destacam na música a sua dimensão de força afectiva, que devemos interpretar como sua dimensão não recognitiva. É enquanto força que a música surge como novidade, produzindo surpresa e instalando um estado de exceção e produzindo a suspensão do tempo, que se revela como desaceleração e espera. Numa direção semelhante, examinamos o caso das oficinas de leitura, que propiciam a experiência com a arte em situação de aprendizagem (KASTRUP, 2000; 2002a; 2002b; 2003). Na experiência literária, o encontro do leitor com o texto se dá num plano de forças. O texto, em sua dimensão de alteridade, aciona no leitor experiências de estranhamento e problematização que ocorrem no plano pré-egóico de afectos. A leitura produz rachaduras, que chamamos, com Deleuze e Guattari (1993), de afectos impessoais, que não se confundem com sentimentos e emoções subjetivas. O encontro com o texto é ocasião para o encontro consigo mesmo, com as forças de alteridade que habitam o próprio leitor. Conforme pode ser observado, a surpresa estética produz tanto um corte que introduz um estado de exceção na subjetividade, quanto uma desaceleração do tempo. Ambos são acolhidos e se tornam gradativamente mais consistentes no decorrer do processo de aprendizagem inventiva que ocorre na oficina literária.

A novidade e a surpresa configuram uma das faces da dupla temporalidade da aprendizagem. A segunda face de sua temporalidade é a sedimentação e o enraizamento. A sedimentação do aprendizado ocorre através do treino, que se apresenta como um conjunto de sessões consecutivas e regulares. Trata-se de um aprendizado passo a passo, mas que nem por isso pode ser dito seqüencial ou quantificável. No processo de treino utilizam-se rotinas e algumas regras básicas. O sentido do treino é criar um campo estável de sedimentação e acolhimento de experiências afectivas inesperadas, que fogem ao controle do eu. A regularidade das sessões tem como efeito a criação de uma familiaridade com tais experiências e, enfim, o desenvolvimento de uma atitude distinta da atitude natural. Cabe também destacar que o tempo do aprendizado ultrapassa a unidade da sessão, incluindo o antes e o depois, ou seja, o movimento de engajamento no processo de treino e os pósefeitos da sessão. São identificados dois movimentos, um mais difícil e que envolve esforço, que é dito rio acima (upstream) e outro mais fácil, feito com menos esforço, denominado rio abaixo, (downstream). Esses dois movimentos imprimem ritmo ao processo, cujo mecanismo é circular.

Depraz, Varela e Vermersch (2003) colocam que "a redução não é apenas a aprendizagem de uma habilidade (apesar de ser isso também), mas o cultivo da habilidade consciente de mudar em relação à atitude natural" (p.99). O processo começa com uma atividade consciente e intencional que se torna, com a prática, espontânea e inintencional. Com a noção de cultivo os autores procuram ressaltar que a aprendizagem resulta no aumento da força e da potência de uma atitude atencional que que já está existe na cognição. Colocam então que, num aprendizado, importa identificar os gestos cognitivos que são relevantes e exercitá-los assiduamente. Afirmam: "Cantores não precisam criar seu aparato vocal, mas sim, sobre a base deste aparato, um instrumento perito 
que os permite cantar (p.100). "Pianistas não precisam construir mãos para tocar, mas levam anos e anos criando mãos de pianistas: fortes, destras, calibradas no espaço, com uma extraordinária precisão" (ibidem). Com o intuito de ressaltar a questão do enraizamento da aprendizagem, a idéia de que o aprendizado se faz sobre o corpo, afirmam que "não envolve invenção". Constata-se então que a noção de invenção da qual procuram se demarcar é a invenção ex-nihilo, que cria o novo a partir do nada (KASTRUP, 1999). Entretanto, quando falamos em invenção recorremos a sua etimologia latina - invenire - que significa compor com restos arqueológicos. Inventar é garimpar o que restava escondido, oculto, mas que, ao serem removidas as camadas históricas que o encobriam, revela-se como já estando lá. As mãos do pianista não se definem nem por seu aparato biológico, nem pela invenção ex-nihilo, mas pela destreza, firmeza, precisão e perícia no movimento dos dedos. A capacidade de desenvolver movimentos tão finos e precisos existia como virtualidade, mas precisou ser cultivado através de uma prática repetida e por um treino disciplinado, para que então pudesse ser criada. O corpo biológico surge como esta reserva de virtualidade, o mesmo valendo para as qualidades da atenção.

A noção de cultivo embaralha a lógica linear do aprendizado, pautando-se na idéia de que "sempre se está à frente de si mesmo". É interessante notar que esta formulação paradoxal constitui uma superação tanto da noção de aprendizagem por acúmulo de novas habilidades, quanto da noção de aprendizagem por perdas. Na noção tradicional de aprendizagem considera-se cada nova habilidade acrescenta-se às anteriores, às quais se associa de modo cumulativo. Na noção de aprendizagem por perdas, a habilidade é considerada a realização de uma dentre um conjunto de possibilidades inatas (MEHLER,1978). Cada realização deste conjunto de possíveis reduz a possibilidade de realização de outras. A noção de aprendizagem por perdas tem o mérito de apontar que a aprendizagem não é unidimensional, que a aquisição de habilidades está sujeita a fenômenos de interdependência que exigem explicação. Todavia, no quadro dessa teoria as condições de possibilidade constituem um campo fechado. No processo de realização de possíveis o problema é de seleção e o que se realiza é durante a aprendizagem é semelhante ao que já estava lá. Já o aprendizado por cultivo é um processo de atualização de uma virtualidade, ganhando o sentido de diferenciação. Trata-se de ativar gestos, aumentando sua força através do exercício e do treino. O pro- blema do tempo do treino é relevante aí, tanto no sentido do aumento da potência gesto cognitivo quanto no sentido da produção de um sentido de apropriação deste gesto, do fazê-lo seu. O novo e o antigo, o que surge e o que já estava lá, não são pares antinômicos, mas se ligam por uma linha de diferenciação e de invenção ${ }^{1}$.

A cognição inventiva não é o mesmo que cognição espontânea. Pode-se dizer que a cognição espontânea é aquela que funciona de acordo com a atitude natural. Embora falemos de uma invenção que não é privilégio de grandes artistas ou cientistas, mas que é distribuída por todos e por cada um, ela depende de cultivo. A invenção não vai por si. Envolve treino aplicado e uma dose de disciplina. Este aprendizado depende, de saída, da suspensão da atitude natural, que é aquela da atitude recognitiva e da consciência intencional. Com ela vem a aprendizagem da atenção, dos dois gestos de redireção e de deixar vir. Começando por mobilizar uma intenção consciente, torna-se aos poucos inintencional. Depraz, Varela e Vermersch apontam que, a longo prazo, uma segunda espontaneidade tem lugar. Esta é definida com a curiosa formulação de um esforço sem esforço, que supera tanto a dicotomia ativo/passivo quanto a dicotomia voluntário/involuntário. A atenção nesta segunda espontaneidade não é ativa, pilotada por um eu, nem passiva, lançada reflexa ou mecanicamente ao sabor dos estímulos do ambiente externo. Partindo da suspensão, o aprendizado estabiliza um tônus atencional singular que envolve a ativação de uma atenção a si e de uma atenção aberta ao encontro de experiências pré-egóicas. Estas duas espécies de atenção encontram-se até certo ponto desativadas, sendo pouco investidas na contemporaneidade. Aumentar sua potência e trabalhar sua estabilização através de práticas de transformação de si é atualizar uma virtualidade através da aliança da surpresa com a regularidade.

Cada sessão, como de resto todo o aprendizado, assume a forma de um círculo. Os três gestos constituem um ciclo onde o movimento é de reincidir, retornar, renovar, reinventar, reiterar, recomeçar. Em última análise, a lógica circular do aprender aponta para o inacabamento do processo, pois não há solução definitiva para o problema da atenção. O aprendizado jamais é concluído e cada sessão abre para um novo aprendizado. Ele é contínuo e permanente, não se fechando numa solução e não se totalizando em sua atualização, precisando por isso ser sempre reativado.

O tratamento do problema da aprendizagem da atenção na cognição inventiva não con- 
duz a uma nova teoria da aprendizagem. Não há uma aprendizagem em geral, mas aprendizados concretos que podem ser muito diversos. Os aprendizados consistem em atualizações concretas do aprender. O que eles possuem em comum é o fato de ocorrerem sempre no seio de uma tradição. A meditação budista, a psicoterapia, a entrevista de explicitação, a formação em filosofia, etc ocorrem através de práticas corporificadas socialmente. Isto significa que, ainda que tendo lugar num indivíduo, a aprendizagem não pode ser dissociada de um contexto social específico, de instituições e dispositivos para sua efetivação. Nessa perspectiva não cabe a oposição entre aprendizagem individual e aprendizagem social. Não se trata de alternativa, mas de duas dimensões indissociáveis. Trata-se de uma experiência individual com dimensão e enraizamento coletivo. Diferente do que propõe a teoria da aprendizagem social de A. Bandura, os indivíduos não podem abrir mão da própria experiência, baseando seu aprendizado na experiência de outros. Como as práticas individuais e as práticas sociais não são independentes, a aprendizagem da atenção configura um problema de cognição coletiva, reunindo tanto o nível préegóico, que é aquém do indivíduo, quanto o nível social, que se situa além do indivíduo e o ultrapassa (MELO, 2004).

\section{A APRENDIZAGEM DA ATENÇÃO E AS PRÁTICAS DE SUSPENSÃO}

O exame cuidadoso e atualizado do funcionamento da atenção revela que esta não é um processo único e homogêneo. O prestar atenção é apenas um dos atos de um processo complexo, que inclui modulações da cognição e da própria intencionalidade da consciência. Do ponto de vista da invenção, verifica-se que uma parte importante do processo ocorre fora de foco, inclui experiências pré-egóicas, opacas e não recognitivas, e não tem no sujeito o centro ou fonte desse processo. Desse ponto de vista, a aprendizagem da atenção envolve a concentração necessária à consistência de tais experiências. Enquanto atenção concentrada, a distração pode ter um papel positivo no processo de aprendizagem inventiva, não sendo mera desatenção e encarnando, em certa medida, o funcionamento da atenção como modulação da intencionalidade da consciência. Representando um afastamento das tarefas pré-definidas e das informações externas, o funcionamento errante da atenção pode dar lugar a experiências de problematização. No entanto, pelo caminho da distração a questão da aprendizagem da atenção resta sem horizonte. A dificuldade de concentra- ção que caracteriza as formas cognitivas predominantes nos dias atuais parece requerer estratégias metodológicas mais concretas. Nesta direção, o método da redução, do qual examinamos o ciclo básico composto de suspensão, redireção e deixar vir, aponta para uma interessante aprendizagem da atenção do ponto de vista da cognição inventiva. A suspensão prepara uma mudança da atenção no que diz respeito à sua direção e à sua qualidade. A experiência com a arte em situação de aprendizagem parece indicar um caminho para atualizações distintas do prestar atenção a tarefas prédefinidas.

Para a invenção, a questão é antes de concentração que de focalização. A subjetividade contemporânea não sofre de falta de foco, mas antes de excesso de focalização. Mas a focalização, por si só, é estéril para a invenção. Por isto a dispersão é um problema. Uma atenção dispersa e ávida de novidade responde automaticamente às informações externas que se proliferam e que convocam uma atenção sempre focada e ao mesmo tempo fugaz. A informação é consumida rapidamente numa busca sem encontro, pois tudo é rapidamente descartado. As práticas de redução, em seu mecanismo circular, podem atualizar um ritmo da atenção que o regime da dispersão atencional, em sua linearidade monótona e homogênea, acaba por encobrir. Trata-se então de recompor, reativar, reinventar um regime de ritmo atencional, que funciona como o ritmo da respiração, alternando tensão e distensão. O método proposto através das práticas de redução exercita o mecanismo circular que está na base da cognição inventiva. Por outro lado, ele fornece pistas da participação da atenção neste processo, além de fornecer indicadores do trabalho sobre a atenção que parece necessário na contemporaneidade. A suspensão que, como dissemos, pode ser desencadeada pela experiência com a arte, prepara a atenção para o encontro com a virtualidade que nos habita, que é fundamental para a bifurcação dos regimes cognitivos existentes e sua reinvenção. Sob suspensão, e passando por este tipo de atenção a si, a cognição opera num nível zero de intencionalidade, acionando uma concentração sem foco e aberta ao presente. $\mathrm{O}$ ritmo atencional revela aí sua dimensão paradoxal: tensionar para soltar, fechar para abrir, concentrar para deixar vir. Em situação de aprendizagem inventiva, a experiência continuada com a arte exercita este ritmo da atenção, cultivando uma outra atitude cognitiva. $\mathrm{O}$ mecanismo circular da aprendizagem aponta que a atenção é ao mesmo tempo condição e efeito de um processo de aprendizagem. Entretanto, mais 
importante do que o problema da atenção que participa de um processo de aprendizagem é o problema do aprendizado da própria atenção, tanto em seu caráter de modulação do foco quanto de concentração aberta.

A aprendizagem da atenção é tão necessária à cognição inventiva quanto a aprendizagem da sensibilidade para o músico. Trata-se de afinar o instrumento para, ao tocar, extrair o som mais puro e mais cristalino de um campo sonoro que existia ainda sem atualização. O papel especial da atenção na preparação da ação sensório-motora explica certamente o grande interesse que este tema desperta nos dias atuais. É por ocupar este lugar privilegiado que a atenção é tão visada pela mídia, pela propaganda e pelo mercado. Mas é também exatamente por este motivo que é tão urgente desvendar seu papel na cognição inventiva e apontar caminhos a serem trilhados através de práticas comprometidas em reativar outras atenções que, fazendo parte de um funcionamento complexo, constituem vias de resistência ao excesso de focalização que nos asfixia no tarefismo fatigante dos dias atuais.

\section{REFERÊNCIAS}

ARVIDSON, P. S.Transformations in consciousness. Journal of Consciousness Studies, 7, n.3, pp.3-26, 2000.

BERGSON, H. La pensée le mouvant. Paris : PUF, 1934/1962.

CAMUS, J-F. (1996) La psychologie cognitive de l'attention. Paris : Armand Colin, 1996.

CRARY, J. Suspensions of perception. Cambridge, Massachusetts/London, England : MIT Press, 2001.

DELEUZE, G. \& GUATTARI, F. Le bergsonime. Paris : PUF, 1991.

DELEUZE, G. \& GUATTARI, F. O que é a filosofia? Rio de Janeiro: Ed. 34, 1993.

DEPRAZ, N, VARELA E VERMERSCH. La réduction à l'épreuve de l'expérience. Études Phénomenologiques, 31/32, pp 165-184. 2002

DEPRAZ, N, VARELA E VERMERSCH.On becoming aware: a pragmatic of experiencing. PhiladelphiaAmsterdam, Benjamin Publishing, 2003.

DUPUY, J-P E VARELA, F. "Círculos viciosos cria- tivos: para compreensão das origens". In: PAUL WATZLAWICK E PETER KRIEG (Orgs) O olhar do observador. Campinas: Editorial Psy II, 1995.

MELO, L. E. (2004) O coletivo como plano de coengendramento do indivíduo e da sociedade. Tese de doutorado. Programa de Pós-Graduação em Psicologia da UFRJ, 2004.

FREUD, S. Recomendações aos médicos que exercem a psicanálise. In: O caso Schreber, Artigos sobre técnica e outros trabalhos. Obras Completas de Freud, vol. XII. Rio de Janeiro: Imago, 1912/ 1969.

JAMES, W. Principios de Psicologia. Buenos Aires: Corrientes, 1890/1945.

KASTRUP, V. A invenção de si e do mundo: uma introdução do tempo e do coletivo no estudo da cognição. Campinas: Papirus,1999.

KASTRUP, V. Sobre livros e leitura: algumas questões sobre aprendizagem em oficinas literárias. Revista do Departamento de Psicologia da UFF, v.12, n.1, pp.65-84, 2000.

KASTRUP, V. Cartografias literárias. Revista do Departamento de Psicologia da UFF v.14, n.2, pp.75$94,2002 \mathrm{a}$

KASTRUP, V. A propos de l'apprentissage de la compétence éthique. Intellectica, 35, pp. 299-322, $2002 b$

KASTRUP, V. (2003) Production de subjectivités en atelier de lecture. Chimères, 49, pp. 95-110.

MEHLER, J. "Conhecer desaprendendo". Em E. Morin e M. Piattelli-Palmarini (Orgs) A unidade do homem, vol.II - O cérebro humano e seus universais. São Paulo: Cultrix.

Mialet, J-P. L'attention. Paris: PUF,1999.

SEARLE, J. O mistério da consciência. São Paulo: Paz e Terra, 1998.

Strawson, G. The "self". Journal of Consciousness Studies, 4 (5-6), pp.5-28, 1997.

VARELA, F. Conhecer. Lisboa: Instituto Piaget,(s/ d).

VARELA, F. Sobre a competência ética. Lisboa: Instituto Piaget, 1995. 
Kastrup, V. "A aprendizagem da atenção na cognição inventiva"

VARELA, F., THOMPSON, E. E ROSCH, E. A mente incorporada. Porto Alegre: Artmed, 2003.

VERMERSCH, P. La prise en compte de la dynamique attentionelle : éléments théoriques. Expliciter, 43, janvier, 2002, pp.27-39, 2002a..

VERMERSCH, P. L'attention entre phénoménologie et sciences expérimentales : éléments de rapprochement. Expliciter, 44, mars, 2002, pp.1443, 2002b.

Virgínia Kastrup é Professora do Programa de PósGraduação em Psicologia da Universidade Federal do Rio de Janeiro. O endereço eletrônico do autora é: vkastrup@terra.com.br Informação complementar. $O$ artigo é resultado de projeto de pesquisa apoiado pelo CNPq.

\section{Virgínia Kastrup} A aprendizagem da atenção

na cognição inventiva.

Recebido: 1/07/2004

$1^{\mathrm{a}}$ revisão: 6/10/2004

Aceite final: 30/11/2004 